\title{
Carbonate-associated Sulfate in Seep-Bivalve Shells: A New Proxy for Isotope Composition of Seawater Sulfate
}

ShangGui GONG ${ }^{1}$, Dong FenG ${ }^{1}$, DuOFu CHEN ${ }^{1}$

${ }^{1}$ Hadal Science and Technology Research Center, College of Marine Sciences, Shanghai Ocean University, Shanghai 201306, China sggong@,shou.edu.cn

Carbonate-associated sulfate (CAS) is increasingly used for tracking the variation of seawater $\delta^{34} S_{\text {sulfate }}$ and $\delta^{18} \mathrm{O}_{\text {sulfate }}$ to reconstruct global sulfur cycle. In contrast to carbonates rocks, CAS in carbonate shells is more likely buffered against diagenetic overprinting due to the resistance of the primary bio-carbonates structure to recrystallization. Here we propose that the seep-bivalve shells, which has been increasingly discovered in Phanerozoic strata, can faithfully record seawater $\delta^{34} \mathrm{~S}_{\text {sulfate }}$ and $\delta^{18} \mathrm{O}_{\text {sulfate. }}$ Two bathymodiolin mussel species with either methanotrophic or thiotrophic symbionts from three different modern seep sites of the South China Sea and the Gulf of Mexico were investigated. The data abstained demonstrate that all seep bivalves regardless of different chemostrophic symbionts display consistently $\delta^{34} \mathrm{~S}_{\mathrm{CAS}}$ and $\delta^{18} \mathrm{O}_{\mathrm{CAS}}$ values that cluster at values corresponding to modern seawater sulfate and exhibit relatively narrow range. Hence, the seep-bivalve can be well severed as a promising proxy for seawater $\delta^{34} \mathrm{~S}_{\text {sulfate }}$ and $\delta^{18} \mathrm{O}_{\text {sulfate. }}$ 